\title{
Morpho-Histological Study of Myocardial Bridges and Their Association with Atherosclerosis
}

\author{
Jaya Raghu Ram Chodimella ${ }^{1}$, Pavitra Kondety ${ }^{2}$ \\ ${ }^{1}$ Department of Pathology, Maharaja's Institute of Medical Sciences, Vizianagaram, Andhra Pradesh, India. \\ ${ }^{2}$ Department of Pathology, Gitam Institute of Medical Sciences and Research, Visakhapatnam, Andhra Pradesh, India.
}

\section{ABSTRACT}

\section{BACKGROUND}

Coronary arteries supply blood to the heart. They run through the epicardial adipose tissue during their course. Occasionally a band of myocardial tissue overlies a segment of the coronary arteries. This band of myocardium overlying the coronary artery is named as Myocardial Bridge (MB). There have been numerous instances of sudden and unexpected cardiac death where the presentation of myocardial bridging was the main clinically pertinent finding post-mortem. We wanted to study the distinct morphological aspects of MBs along with the structural composition of the coronary vessel present beneath, in front of and past the myocardial bridge.

\section{METHODS}

Microscopy and morphometry were utilized to detail the distinct morphological characteristics of myocardial bridges as well as to take a closer look at the structural composition of the coronary vessel present beneath, in front of and past the myocardial bridge being evaluated. Three segments of the left anterior descending artery (LAD) were utilized to glean testable samples. These samples are as follows: (A) located proximally to the bridge at a distance of $8 \mathrm{~mm}$, (B) alongside the bridge and $(C)$ located distally from the bridge at a distance of $8 \mathrm{~mm}$.

\section{RESULTS}

Prevalence of MB was found to be $40 \%$. Male to female ratio was 7:1. 87.5 \% of the hearts have single MB, $10 \%$ have double MB, $2.5 \%$ have triple MB. Most common vessel affected is LAD. The MBs ranged in length from $4.4 \mathrm{~mm}$ to $45 \mathrm{~mm}$ with a length of $12.67 \mathrm{~mm}$ being the quantifiable mean. Thickness of MB ranged from 0.4 to $1.9 \mathrm{~mm}$ with mean thickness of $1.11 \mathrm{~mm}$. The component of the coronary artery that was bridged often showed a diminished tunica intima compared to similar segments taken from proximal and distal sites. It should be noted that the proximal segment is predisposed to atherosclerotic presentation on account of myocardial bridging.

\section{CONCLUSIONS}

A myocardial bridge leads to detrimental changes in the vessel which in turn leads to early presentation of atherosclerosis, arrhythmias, myocardial infarctions and in severe cases, sudden death. Myocardial bridging is frequently localized in the LAD. It can have significant effects on the overall health.

\section{KEY WORDS}

Myocardial Bridging, Coronary Atherosclerosis, Coronary Artery Disease, Myocardial Infarction
Corresponding Author: Dr. Pavitra Kondety, Assistant Professor, Department of Pathology,

Gitam Institute of Medical Sciences and Research, Visakhapatnam,

Andhra Pradesh, India

E-mail: kondetypavitra@gmail.com

DOI: $10.14260 / \mathrm{jemds} / 2020 / 681$

How to Cite This Article:

Chodimella JRR, Kondety P. Morphohistological study of myocardial bridges and their association with atherosclerosis. J Evolution Med Dent Sci 2020;9(42): 3102-3106, DOI:

10.14260/jemds/2020/681

Submission 18-02-2020,

Peer Review 11-09-2020,

Acceptance 18-09-2020,

Published 19-10-2020.

Copyright (C) 2020 Jaya Raghu Ram Chodimella et al. This is an open access article distributed under Creative Commons Attribution License [Attribution 4.0 International (CC BY 4.0)] 


\section{BACKGROUND}

There have been numerous instances of sudden and unexpected cardiac death where the presentation of myocardial bridging was the main clinically pertinent finding post-mortem. Numerous studies have been done to establish the association between the presence of $\mathrm{MB}$ and cardiovascular disease, arrhythmias and sudden cardiac death.

The coronary arteries supply blood to the heart. They run through the epicardial adipose tissue during their course. Occasionally a band of myocardial tissue overlies a segment of the coronary arteries. This band of myocardium overlying the coronary artery is named as Myocardial Bridge (MB). ${ }^{1,2}$ Myocardial bridges have been reported to exist exclusively in the mid portion of left anterior descending artery (LAD) by few a studies.3,4 Many authors considered MB as a benign anatomical variant rather than a congenital anomaly.4,5,6 But this was challenged by other studies. These studies found that there was significant correlation between presence of myocardial bridging and the presentation of cardiovascular heart disease, arrhythmias and sudden cardiac death. 2,3,4,7-12

MB are often localized to the middle segment of the LAD. Branches that split away in a diagonal fashion showcase $18 \%$ involvement while marginal branches showcase a higher degree of involvement at $40 \%$. Myocardial bridging can present either in single or multiple formats with multiple MBs occurring within the same coronary artery and its corresponding branches or another by its side. ${ }^{7}$ Ferreira et al. ${ }^{13}$ divided the myocardial bridging into two types: superficial and deep muscle. The superficial type presents with no coronary flow constriction during systole; while the deep type has the possibility of coronary artery compression, resulting in reduced blood flow and potential induction of myocardial ischemia.

There have been incidences of sudden death due to cardiac causes where myocardial bridging was the only significant finding on autopsy. Few reports show atheromatous changes in the coronary artery proximal to the MB with absence of atheromatous changes in the tunnelled coronary artry. ${ }^{14}$ Occasionally myocardial bridges are reported to cause angina or myocardial infarction. ${ }^{15}$ The autopsy of these patients ( $6 \%$ of patients with myocardial infarction) did not reveal the presence of atherosclerosis. This left only myocardial bridges as the causative factor. ${ }^{16}$ Although post-mortem detection of myocardial bridges is seen in $30-40 \%$ of cases, only $5 \%$ of the general population is reported to have narrowing of coronary vessels. ${ }^{17}$ Myocardial akinesia alongside a myocardial infarction could potentially decrease the rate at which MB are detected. ${ }^{16}$

A majority of MB are silent clinically. But the longest and deepest ones may exert significant pressure in the underlying coronary vessels to reduce myocardial blood supply. The pressure applied by the MB during the cardiac systole and deceleration in the development of coronary atherosclerosis may reduce heart diseases. The haemodynamic stress applied by the presence of $\mathrm{t}$ MB contraction may be the important factors in the occurrence of coronary heart disease (CHD) where MB are existent.7,18,19 Several studies have recorded the correlation of MB with CHD such as myocardial ischemia, arrhythmia, acute coronary syndromes or sudden death.18,19 From a histopathological and clinical point of view, the presence of MB protects the tunnelled segment of coronary artery from the development of atherosclerosis by 3 main mechanisms, including: low tensile stress, high shear stress and decrease tension of the coronary wall.20 Therefore, the MB maybe considered as a protective factor from atherosclerosis through the surrounding myocardium that acts as haemodynamic microenvironment within the bridges. ${ }^{19}$

A distinct link between myocardial bridging and the development of atherosclerosis proximal to a tunnelled artery have been demonstrated pathologically. 4,21-23 However, as catheter coronary angiography cannot detect the presence of myocardial bridging, it does not allow for a causal relationship to be established between myocardial bridging and coronary atherosclerosis in vivo. ${ }^{24}$

\section{Objectives}

The primary goal of this study was to detail the distinct morphological aspects of MBs as well as to take an in depth look at the structural composition of the coronary vessel present beneath, in front of and past the myocardial bridge being evaluated.

\section{METHODS}

A descriptive cross-sectional study was carried out with nonrandom convenient sampling. One hundred preserved hearts were scrutinized. These adult hearts were sourced from Department of Anatomy, Maharaja's Institute of Medical Sciences (MIMS), Vizianagaram, Andhra Pradesh. The ethics review committee of MIMS cleared the study when contacted for approval. The perivascular adipose tissue was vivisected to reveal the coronary vessels. These vessels were traced from the sinus of Valsalva to their distal points. Intramyocardial segments (coronary tunnelling) were identified, traced, and recorded. Measurements were taken of the length and the thickness (at the intermediate zone) of each bridge. Their distances from the sinus of Valsalva were measured as well using a digital Vernier ( $0.1 \mathrm{~mm}$ precision).

The hearts were harvested within 72 hours from death. They were closely observed for any degradative changes and autolytic components. These hearts were then subjected to morphometry. Light microscopy was employed to confirm the existence of significant bridging.

Three components of the tunnelled artery were taken for sampling. First one was taken $8 \mathrm{~mm}$ proximal to the bridge second one was taken containing the bridge and the third on was taken $8 \mathrm{~mm}$ distal to the bridge. All samples were removed en block. They were dehydrated using alcohol solutions of increasing grades and embedded in paraffin wax. $7 \mu \mathrm{m}$ thick sections (on slides) were taken from representative areas. Haematoxylin and Eosin and VerhoffVan-Gieson stains were done on the sections. Masons trichrome staining was also utilized to demonstrate structural details. Morphometry was done with point counting was done to measure the thickness of the tunica intima, media and luminal area. The stained segments were observed under an eye piece with the morphometer. The grid points that fell on the tunica, intima, media and lumen were counted and recorded. 


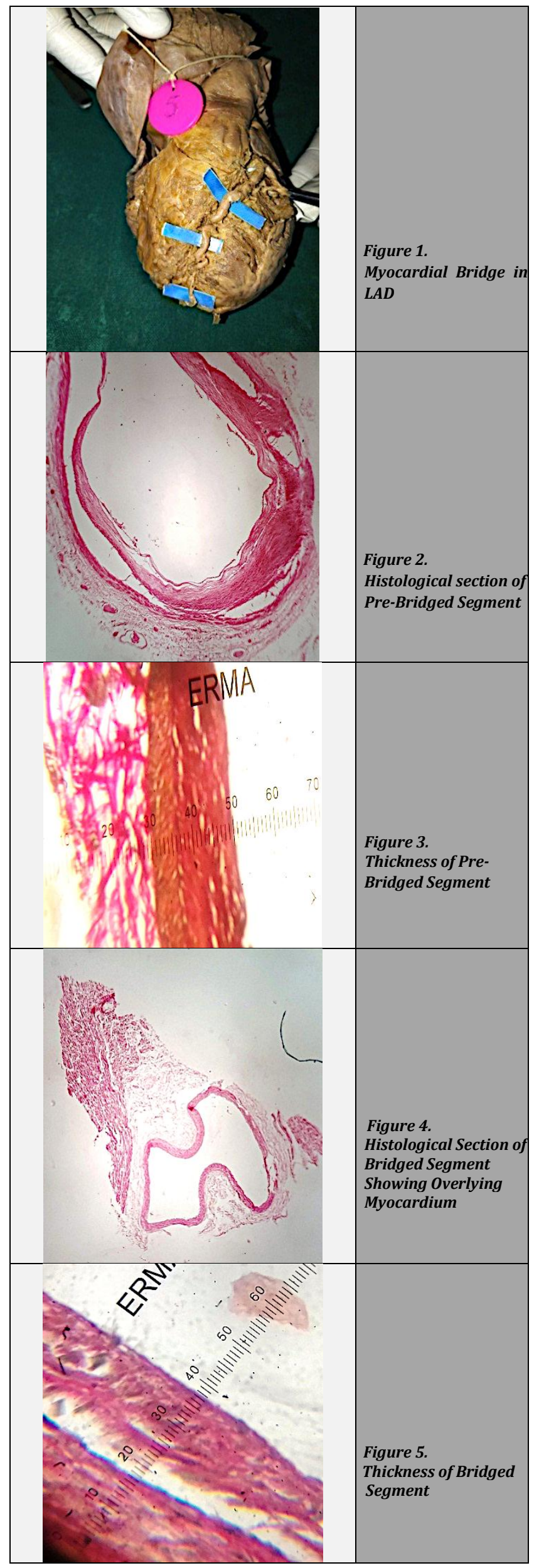

\section{Statistical Analysis}

The means and variances were investigated and analyzed utilizing the Statistical Package for Social Sciences (SPSS) for Windows version 11.5.0 Chicago, Illinois 2002. Analysis of variance was used to compare the mean thickness of the intimae of the pre, juxta and post-bridged segments of the LAD. A recorded $p$ value that was $<0.05$ was considered statistically significant.

\section{RESULTS}

In the present study the prevalence was found to be $40 \%$. Male to female ratio was 7:1. Age group in the study was from 45 - 79 years with mean age of 69.14 years. $87.5 \%$ have single MB, $10 \%$ have double MB, $2.85 \%$ have triple MB. Most common vessel effected is LAD, $100 \%$. Most common site of LAD affected is middle $1 / 3^{\text {rd }}$ in $70 \%$, with proximal $1 / 3^{\text {rd }}$ in $20 \%$, and distal $1 / 3^{\text {rd }}$ in $10 \%$ of cases.

Length of MB ranged from $4.4 \mathrm{~mm}$ to $45 \mathrm{~mm}$ with mean of $12.67 \mathrm{~mm}$. Thickness of MB ranged from 0.4 to $1.9 \mathrm{~mm}$ with mean thickness of $1.11 \mathrm{~mm}$. Distance of MB from coronary ostia is from 22.5 to $54.5 \mathrm{~mm}$ with mean distance of 32.15 $\mathrm{mm}$.

\begin{tabular}{|ccccc|}
\hline Characteristic (mm) & Mean & SD & Minimum & Maximum \\
Length of MB & 12.67 & 8.24 & 4.4 & 45 \\
Thickness of MB & 1.11 & 0.32 & 0.4 & 1.9 \\
Location of MB from Coronary Ostia & 32.15 & 5.71 & 22.5 & 54.5 \\
\hline \multicolumn{2}{|c|}{ Table 1. Morphological Characteristics of Myocardial Bridges } \\
\hline
\end{tabular}

The following table shows morphometry of bridged segment, pre bridge segment and post bridge segment.

\begin{tabular}{|c|c|c|c|c|c|c|}
\hline \multirow{2}{*}{$\begin{array}{l}\text { Mean Values } \\
\text { in } \mathbf{~ m m}\end{array}$} & \multicolumn{2}{|c|}{$\begin{array}{l}\text { Pre-Bridge } \\
\text { Segment }\end{array}$} & \multicolumn{2}{|c|}{$\begin{array}{l}\text { Bridged } \\
\text { Segment }\end{array}$} & \multicolumn{2}{|c|}{$\begin{array}{c}\text { Post Bridge } \\
\text { Segment }\end{array}$} \\
\hline & Mean & SD & Mean & SD & Mean & SD \\
\hline External Diameter & 3.23 & 0.56 & 2.38 & 0.48 & 2.67 & 0.48 \\
\hline Internal Diameter & 1.93 & 0.39 & 1.41 & 0.46 & 1.57 & 0.51 \\
\hline \multicolumn{7}{|c|}{$\begin{array}{c}\text { Table 2. Diameters of Pre-Bridge, Bridged and } \\
\text { Post Bridge Segments }\end{array}$} \\
\hline
\end{tabular}

The following table shows the intima and media thickness of pre-bridge, bridged and post-bridge segments with respective intima media thickness ratio.

\begin{tabular}{|c|c|ccccc|}
\hline $\begin{array}{c}\text { Mean Values } \\
\text { in } \mathbf{~ m m}\end{array}$ & \multicolumn{2}{|c}{ Intima } & \multicolumn{3}{c|}{ Media } & \multirow{2}{*}{ I:M Ratio } \\
& Mean & SD & Mean & SD & \\
Pre-Bridge & 1.35 & 0.68 & 1.06 & 0.38 & 1.3 \\
Bridge & 0.31 & 0.07 & 0.86 & 0.24 & 0.8 \\
Post Bridge & 0.31 & 0.07 & 0.94 & 0.25 & 0.9 \\
\hline Table 3. Intima and Media & Thickness of Pre-Bridge, \\
\\
Bridged and Post Bridge Segments \\
\hline
\end{tabular}

\section{DISCUSSION}

Findings in this particular study are homogenous with gathered literature from prior necropsy studies. The study done by Loukas $\mathrm{M}$ et $\mathrm{al}^{25}$ on 200 hearts showed a total of 81 bridges with MBs being found in 69 hearts (34.5\%). A singular bridge was found in 59 of the gathered while 10 showed multiple bridging ( 8 with double bridges and 2 with 
triple bridges). Ferreira $\mathrm{AG}$ et $\mathrm{al}^{13}$ found that single and multiple MB were seen in 50 (55.6\%) out of 90 hearts. The LAD was consistently the most commonly affected artery.

In our study prevalence was found to be $40 \%$. The middle LAD coronary artery was the site where myocardial bridges frequently consolidated in the current study.

Polacek et $\mathrm{al}^{26}$ showcased that the muscular bridges organized by ventricular myocardium were regularly 10 to $20 \mathrm{~mm}$ long, up to $5 \mathrm{~mm}$. thick, and frequently localized in the proximal half of the anterior descending branch (60\%). They also reported that the stretch of the artery before the bridge normally corresponds to the site at which occlusions most frequently occur. The intima of the artery under the bridge was usually thin, whereas before the bridge it is strongly hyperplastic. This presentation can be sometimes be seen behind the bridge as well.

We were able to note that bridged segments of the coronary artery tended to exhibit a constricted and limited tunica in contrast to the proximal and distal segments of the same vessel.

Based on the findings detailed previously in the course of the study, assertions have been made that the myocardial bridge can be held accountable for predisposition of the proximal segment of the artery to atherosclerosis. ${ }^{6}$

In contrast, the tunneled segment is protected by the bridge from atherosclerosis. It presents with a reduced intima when compared to the distal segment. Compression of the segment underlying the MB can potentially be associated with an increased resistance to blood flow. This corresponds to reduced mural tension for any given tension as surmised by the Laplace principle. ${ }^{27,28}$

The perivascular spaces contain adipose tissue around the bridged CA. This can be recognized as a cushion of sorts which mitigates the constricting forces on the affected vessels during systole.

\section{CONCLUSIONS}

Presence of MB results in modification of the pre-bridge section of the coronary segment that is comparable to early atherosclerotic presentation. Prevalence of myocardial bridging is around $40 \%$ in the general population. They are more common in males. Myocardial bridging is frequently localized in the left anterior descending coronary artery. A significant number of the gathered hearts show only one MB, although multiple MB are known to occur. Presentations of MB can be associated with several concerning cardiovascular events, such as arrhythmias, myocardial infarctions, and in severe cases, sudden death.

Symptomatic patients should be subjected to conservative treatment with the plan progressing to surgical intervention depending on the individual condition of the patient in question. Recognition and general awareness of the morphological characteristics and pathological effects of myocardial bridging on the epicardial coronary branches allow clinicians and cardiologists to formulate better treatment modalities and surgical interventions.
Data sharing statement provided by the authors is available with the full text of this article at jemds.com.

Financial or other competing interests: None.

Disclosure forms provided by the authors are available with the full text of this article at jemds.com.

\section{REFERENCES}

[1] Reyman HC. Dissertatio de vasis cordis propriis. Bibl Anat 1737;2:359-78.

[2] Geiringer E. The mural coronary. Am Heart J 1951;41(3):359-68.

[3] Angelini P, Trivellato M, Donis J, et al. Myocardial bridges: a review. Prog Cardiovasc Dis 1983;26(1):7588.

[4] Ishii T, Asuwa N, Masuda S, et al. The effects of a myocardial bridge on coronary atherosclerosis and ischaemia. J Pathol 1998;185(1):4-9.

[5] Konen E, Goitein 0, Di Segni E. Myocardial bridging, a common anatomical variant rather than a congenital anomaly. Semin Ultrasound CT MR 2008;29(3):195-203.

[6] Ripa C, Melatini MC, Olivieri F, et al. Myocardial bridging: a forgotten cause of acute coronary syndrome - a case report. Int J Angiol 2007;16(3):115-8.

[7] Möhlenkamp S, Hort W, Ge J, et al. Update on myocardial bridging. Circulation 2002;106(20):2616-22.

[8] Kim SY, Lee YS, Lee JB, et al. Evaluation of myocardial bridge with multidetector computed tomography. Circ J 2010;74(1):137-41.

[9] Kalaria VG, Koradia N, Breall JA. Myocardial bridge: a clinical review. Catheter Cardiovasc Interv 2002;57(4):552-6.

[10] Gow RM. Myocardial bridging: does it cause sudden death? Card Electrophysiol Rev 2002;6(1-2): 112-4.

[11] Morales AR, Romanelli R, Tate LG, et al. Intramural left anterior descending coronary artery: significance of the depth of the muscular tunnel. Hum Pathol 1993;24(7):693-701.

[12] Corrado D, Thiene G, Cocco P, et al. Non-atherosclerotic coronary artery disease and sudden death in the young. Br Heart J 1992;68(6):601-7.

[13] Ferreira AG, Trotter SE, Konig B, et al. Myocardial bridges: morphological and functional aspects. Br Heart J 1991;66(5):364-7.

[14] Saidi HS, Olumbe AO, Kalebi A. Anatomy and pathology of coronary artery in adult black kenyans. East Afr Med J 2002;79(6):323-7.

[15] Burnsides C, Edwards JC, Lansing AI, et al. Artherosclerosis in intramural and extramural portions of coronary arteries in human heart. Circulation 1956;13(2):235-41.

[16] Widmann JD, Cox SL, Roongsritong C. Unappreciable myocardial bridge causing anterior myocardial infarction and postinfarction angina. South Med J 2003;96(4):400-402.

[17] Resar JR, Brinker JA. Bridge work. Cathet Cardiovasc Diagn 1997;41(4);421-2.

[18] Bourassa MG, Butnaru A, Lesperance J, et al. Symptomatic myocardial bridges: overview of ischemic mechanisms and current diagnostic and treatment strategies. J Am Coll Cardiol 2003;41(3):351-9. 
[19] Ishikawa Y, Akasaka Y, Suzuki K, et al. Anatomic properties of myocardial bridge predisposing to myocardial infarction. Circulation 2009;120(5):376-3.

[20] Chatzizisis YS, Giannoglou GD. Myocardial bridges spared from atherosclerosis: overview of the underlying mechanisms. Can J Cardiol 2009;25(4):219-22.

[21] Ge J, Erbel R, Gorge G, et al. High wall shear stress proximal to myocardial bridging and atherosclerosis: intracoronary ultrasound and pressure measurements. Br Heart J 1995;73(5):462-5.

[22] Ishikawa Y, Akasaka Y, Ito K, et al. Significance of anatomical properties of myocardial bridge on atherosclerosis evolution in the left anterior descending coronary artery. Atherosclerosis 2006;186(2):380-9.

[23] Ishii T, Hosoda $Y$, Osaka T, et al. The significance of myocardial bridge upon atherosclerosis in the left anterior descending coronary artery. J Pathol 1986;148(4):279-91.
[24] Nakaura T, Nagayoshi Y, Awai K, et al. Myocardial bridging is associated with coronary atherosclerosis in the segment proximal to the site of bridging. J Cardiol 2014;63(2):134-9.

[25] Loukas M, Curry B, Bowers M, et al. The relationship of myocardial bridges to coronary artery dominance in the adult human heart. J Anat 2006;209(1):43-50.

[26] Polacek P. Relation of myocardial bridges and loops on the coronary arteries to coronary occlusions. Am Heart J 1961;61(1):44-52.

[27] Shotar A, Busuttil A. Myocardial bars and bridges and sudden death. Forensic Sci Int 1994;68(3):143-7.

[28] Bandyopandhyay B, Kulkarni S, Mody R, et al. Extrinsic obstruction of the main coronary arteries in a child with hypertrophic cardiomyopathy. Indian Heart J 2002;54(2):202-5. 